\title{
Olfactory Fingerprints for Major Histocompatibility Complex- Determined Body Odors II: Relationship among Odor Maps, Genetics, Odor Composition, and Behavior
}

\author{
Michele L. Schaefer, ${ }^{1,2,3}$ Kunio Yamazaki, ${ }^{4}$ Kazumi Osada,, ${ }^{4,5}$ Diego Restrepo,, ${ }^{1,2,3}$ and Gary K. Beauchamp ${ }^{4}$ \\ ${ }^{1}$ Neuroscience Program, ${ }^{2}$ Rocky Mountain Taste and Smell Center, ${ }^{3}$ Department of Cellular and Structural Biology, \\ University of Colorado Health Sciences Center, Denver, Colorado 80262, ${ }^{4}$ Monell Chemical Senses Center, Philadelphia, \\ Pennsylvania 19104, and 5Self Medical Laboratories, Taisho Pharmaceutical Company, Oomiya, 330-8530, Japan
}

\begin{abstract}
The olfactory system detects small differences in the composition of natural odorants, made up of hundreds of molecules. Odorous quality is hypothetically represented by a combinatorial code: activation of distinct but overlapping subsets of olfactory receptors resulting in activation of a distinct subset of glomeruli in the main olfactory bulb (MOB). Here we show that modification of a single gene (the $\mathrm{K}$ gene of the major histocompatibility locus), which results in a subtle change in the odiferous quality of urine, causes a small but significant change in the composition of urine volatiles and consequently the evoked glomerular activation pattern in the MOB. The magni-
\end{abstract}

Individual body scents present in urine are influenced by genetic differences. The most robust contributors occur at highly polymorphic sites, including the major urinary proteins (MUPs) (Hurst et al., 2001) found on chromosome 4 (Bishop et al., 1982) and the major histocompatibility complex (MHC or $\mathrm{H}-2$ in mice) (Boyse et al., 1987) on chromosome 17. These genes influence the composition of body odors that enable mice to distinguish one another according to the constellation of alleles that they carry throughout this part of the genome. By using highly inbred mice we are able to eliminate any differential contribution by the MUPs and can focus on the role of the MHC in individual recognition. More than one gene in the MHC is concerned in constituting individual odor phenotypes: genetic differences in all the class I genes $(\sim 36)$, and of a single class I gene alone, each independently confer individuality of scent (see Fig. 1) (Boyse et al., 1987).

We reported previously that the patterns of evoked neural activity in the main olfactory bulb (MOB) differ between the congenic urine odors from $\mathrm{H}-2^{\mathrm{k}}$ and $\mathrm{H}-2^{\mathrm{b}}$ mice, which differ at all their alleles within the MHC but otherwise have a common genetic background (Schaefer et al., 2001b). Those results were consistent with the hypothesis that distinct spatial activity patterns or "odor maps" are part of the neural basis for perceptual

\footnotetext{
Received June 10, 2002; revised July 26, 2002; accepted Aug. 12, 2002.

This work was supported by grants from the National Institute of Mental Health (MH12438) to M.L.S., the National Institute of Deafness and Communication Disorders (DC00566, DC00244, and DC004657) to D.R., and the National Science Foundation (IBN 0112528) and Defense Advanced Research Program Agency (MDA972-02-C-0002) to K.Y. and G.K.B. We thank the anonymous reviewers for insightful comments.

Correspondence should be addressed to Dr. Diego Restrepo, Department of Cellular and Structural Biology, University of Colorado Health Sciences Center, 4200 East Ninth Avenue, Room 4505 SOM, Denver, CO 80262. E-mail: diego.restrepo@uchsc.edu.

Copyright ( 2002 Society for Neuroscience 0270-6474/02/229513-09\$15.00/0
}

tude of disparity between urine-evoked glomerular activation patterns is predictive of the extent of (1) the genetic difference among the urine donors, (2) the difference in the chemical composition of urine, and (3) the odor detector's ability to discriminate. These data on natural odors are consistent with the combinatorial code hypothesis and identify subsets of glomeruli that are apt to play a significant role in mediating individual recognition.

Key words: major histocompatibility complex; olfactory; urine; coding; recognition; c-fos discrimination of odor quality and intensity (Xu et al., 2000). Our findings, which further implicated the MOB as important in the recognition of individual body odors, was additionally supported when the vomeronasal organ (VNO), also implicated in recognition of individual odor types, was removed and did not disrupt recognition of MHC-determined individual odor types (Wysocki et al., 2001). Although our previous manuscript was enticing, it did not definitively identify the MHC class I genes as being responsible for the distinct spatial patterns of glomerular activity. The MHC spans $\sim 2 \mathrm{~cm}$ and contains many genes, including $\sim 36$ MHC class I, MHC class II, olfactory receptors, etc. (see Fig. 1).

Here we investigate whether the composition of urine volatiles and their spatial representations in the $\mathrm{MOB}$ are altered by differences at a single MHC class I gene. Specifically, we asked whether single genetic differences in the $\mathrm{H}-2 \mathrm{~K}$ class I gene $\left(\mathrm{K}^{\mathrm{b}}\right.$ versus $\mathrm{K}^{\mathrm{bm} 1}$ versus $\mathrm{K}^{\mathrm{bm} 8}$ ), known to give rise to unique scents, could alter the composition of urine volatiles and their spatial representation within the MOB. The wild-type $\mathrm{K}^{\mathrm{b}}$ gene along with the spontaneous mutants $\mathrm{K}^{\mathrm{bm} 1}$ and $\mathrm{K}^{\mathrm{bm} 8}$ all encode functional class I glycoproteins that impart to each mouse a unique body scent (Yamazaki et al., 1983; Schumacher et al., 1992). These proteins differ from each other by only a few amino acids in the highly polymorphic peptide-binding region of the molecule. Notice that $\mathrm{H}-2 \mathrm{~K}$ denotes a single gene, whereas $\mathrm{H}-2^{\mathrm{k}}$ indicates the MHC haplotype (see Fig. 1).

\section{MATERIALS AND METHODS}

Odor exposure. Donor male urine was collected while applying gentle abdominal pressure and stored at $-20^{\circ} \mathrm{C}$ until needed. Urine was obtained under exactly the same conditions as the urine collected for previous behavioral experiments (Yamazaki et al., 1983, 1990). Briefly, each sample was composed of urine from one to three individual animals. For most samples, these individuals were different (i.e., different samples were taken from different groups of one to three donors). Female odor 
recipients ranged in age from 12 to 20 weeks, a period of time during which the olfactory bulb changes little, if at all (Pomeroy et al., 1990). Awake and behaving nonestrous female BALB/C $\left(\mathrm{H}-2^{\mathrm{d}}\right)$ mice were placed in a 51 glass jar and exposed to humidified fresh air for $40 \mathrm{~min}$ at $3 \mathrm{l} / \mathrm{min}$. The fresh air controls were exposed for an additional $30 \mathrm{~min}$. Experimental animals then were exposed to age-matched male urine odor from one of four different $\mathrm{H}-2$ haplotypes (C57BL/6, H-2 ${ }^{\text {b }}$; B6.AKR, H-2 $2^{\mathrm{k}}$; C57BL/6, H-2 ${ }^{\mathrm{bm} 8}$; C57BL $/ 6, \mathrm{H}-2^{\mathrm{bm} 1}$ ). Raw data for four of eight $\mathrm{H}-2^{\mathrm{b}}$ and four of six $\mathrm{H}-2^{\mathrm{k}}$ mice were obtained from our previous report (Schaefer et al., 2001b). All exposures were performed using a $20 \% \mathrm{v} / \mathrm{v}$ of urine (1:5 dilution). This dilution was chosen on the basis of a paradigm used in a behavioral discrimination assay (Yamazaki et al., 1999). Odors were delivered over a $30 \mathrm{~min}$ period ( $3 \mathrm{~min}$ odor on followed by 2 min odor off) because $c$-fos mRNA, the upregulation of which was used as a measure of odor-evoked activity (see below), has a half-life of $\sim 15-20 \mathrm{~min}$. Because $c$-fos mRNA increases essentially as if it were an integral of electrical activity, and because the olfactory response adapts, the majority of the $c$-fos signal would be expected to arise from the first minute of exposure in each repeated 3 min exposure. Moreover, Guthrie and Gall (1993) demonstrated that rats exposed to peppermint odor for 5 min displayed $c$-fos activation patterns similar in extent (albeit more noisy) than the pattern displayed by rats exposed to peppermint odor for $30 \mathrm{~min}$. We contend that we are measuring the response during the first several minutes of exposure. Several minutes of exposure are necessary to integrate the amount of odor-induced levels of $c$-fos mRNA produced so as to obtain a decent signal-to-noise ratio. All procedures were done in compliance with standards of the Animal Care and Use Committees of the University of Colorado Health Sciences Center and the Monell Chemical Senses Center.

Gas chromatography. Methods used for urine sample preparation for gas chromatography were similar to those described in Singer et al. (1997). Samples from individual male mice of the four inbred strains

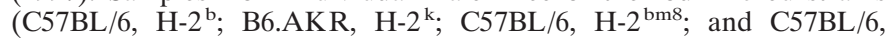
$\mathrm{H}-2^{\mathrm{bm} 1}$ ) were collected as described previously (Yamazaki et al., 1983, 1990). The mouse urine was pretreated by centrifugal ultrafiltration in Centricon-10 tubes (Amicon; 10,000 MW cutoff) at $4500 \times g(6500 \mathrm{rpm})$ at $5^{\circ} \mathrm{C}$, acidified to a $\mathrm{pH}$ of $4.4-4.6$ by adding $200 \mathrm{mg}$ of $\mathrm{KH}_{2} \mathrm{PO}_{4}-\mathrm{H}_{2} 0$, and extracted with $15 \mathrm{ml}$ of HPLC grade diethyl ether (Aldrich) for $2 \mathrm{hr}$ by constant agitation on a Tekmar VXR flatbed shaker (Janke \& Kunkel, Staufen, Germany). Samples were concentrated to $\sim 0.5 \mathrm{ml}$ in a SpeedVac concentrator and then lyophilized to remove any remaining water. They were then redissolved in $100 \mu$ l of methyl acetate.

Chemical analysis was performed on a Varian 3300C gas chromatograph (GC). The GC was fitted with a Restek Stabilwax column $(30 \mathrm{mt} \times$ $0.32 \mathrm{~mm} \times 0.5 \mu \mathrm{m})($ Restek, Bellefonte, PA). The carrier gas was helium at 13 psi. Oven temperature was maintained at $80^{\circ} \mathrm{C}$ for $2 \mathrm{~min}$ and then programmed at $5^{\circ} \mathrm{C} / \mathrm{min}$ to $240^{\circ} \mathrm{C}$. The injector temperature was held constant at $220^{\circ} \mathrm{C}$. Detection was by flame ionization. Analysis of peak heights (as percentage of total) was undertaken for 41 representative compounds present in urine of all individuals in each haplotype. Thus for each individual sample (composed of urine from one to three individual donors) for each of the four genotypes, a relative pattern of the 41 volatiles was determined.

Measurement of odor-evoked activity. Mice were killed immediately after odor exposure and perfused with $4 \%$ paraformaldehyde, and the olfactory bulbs were harvested. Transverse sections $(18 \mu \mathrm{m})$ of the MOB were cut on a cryostat and collected onto glass slides (Schaefer et al., 2001a). In situ hybridization analysis of $c$-fos mRNA expression was performed on every fourth section for a total of 36 sections representative of nearly the entire length of the bulb. It should be noted here that although the $c$-fos as well as $\left[{ }^{14} \mathrm{C}\right] 2$-deoxyglucose methods are limited because they are static and indirect measures of activity, they are the only methods that can currently be used to measure activity in the entire bulb in awake behaving animals. These advantages currently outweigh the disadvantages of these measurement methods. Sections were processed for colorimetric in situ hybridization localization of $c$-fos mRNA using a digoxigenin-labeled riboprobe and alkaline phosphatase (Roche Molecular Biochemicals, Indianapolis, IN) as described elsewhere (Guthrie and Gall, 1995a). The antisense $c$-fos cRNA was transcribed from a mouse recombinant cDNA clone to generate a 535 base transcript corresponding to positions $1842-1944$ and 2061-2493 of the mouse $c$-fos gene. Increases in $c$-fos mRNA were measured in the juxtaglomerular cells (periglomerular and external tufted cells) surrounding glomeruli (Guthrie et al., 1993; Guthrie and Gall, 1995a,b). Glomeruli were scored as positive when an arc of labeled juxtaglomerular cells spanning either $180^{\circ}$ in any orientation or two $90^{\circ}$ arcs spanning any region not abutting the external plexiform layer were identified (Schaefer et al., 2001b).

Mapping the patterns of odor-evoked activity. The coordinates for each positive glomerulus are given in rostrocaudal distance and radial angle around a section. Anatomical landmarks determine the origins for the radial measurements. The first section is defined by the point at which complete mitral cell and external plexiform layers can be identified (Johnson and Leon, 1996; Johnson et al., 1998, 1999; Schaefer et al., 2001a). The $0-180^{\circ}$ axis was drawn parallel to the more ventral aspect of the subependymal layer. For the rostral sections, the origin was taken as one-third the distance from the dorsal to the ventral mitral cell layer. At the level of the accessory olfactory bulb (AOB), the origin is defined as the point just ventral to the AOB. Past the AOB the origin is placed at the granular cusp.

Binning and smoothing glomerular activation maps. The number of positive glomeruli is presented as uncorrected "raw" values (Schaefer et al., 2001b). Briefly, by processing every fourth section we are sampling every $72 \mu \mathrm{m}$. All of the positive events (glomeruli) for each section are arrayed into bins of $10^{\circ}$ and $72 \mu \mathrm{m}$. These data are then summated using a kernel of 3 (Schaefer et al., 2001b). The kernelled data are then visualized as a color contour plot constructed in Microcal Origin 6.0. A self-extractable compressed file containing the program ToMatrix to transform and analyze glomerular activation data can be downloaded from the Restrepo Lab homepage at http://www.uchsc.edu/ctrsinst/ rmtsc/restrepo/ToMatrixPackage.exe by clicking on the biomedical information and tools tab.

Point-by-point Mann-Whitney test. As described above, all datasets consisted of rectangular arrays of bins each containing the number of positive glomeruli within a $10^{\circ}$ and $72 \mu \mathrm{m}$ interval. To estimate central tendency, the average was calculated binwise. To determine the statistical significance of differences among spatial patterns, we used a binwise normalized Mann-Whitney $U$ test (Siegel, 1956; Johnson and Leon, 1996). To normalize, we computed the average patterns, performed a least squares fit of one of the patterns to the other times a factor, and normalized the second data set using the least squares fit factor. This is similar to the method used in Schaefer et al. (2001b). Results were similar with a raw Mann-Whitney (data not shown). For each bin, the MannWhitney $p$ value was calculated by sorting an estimation of $U$ for all values within nine adjacent bins. Many of the methods used in calculations were taken from Numerical Recipes in C (indicated within the ToMatrix program) (Press et al., 1992). We used a false discovery rate (FDR) critical value to define the $p$ value below which we consider the differences to be significant. The FDR is a critical value adjusted for the multiple comparisons that take place in each point-by-point MannWhitney test (Curran-Everett, 2000). The FDR procedure does not control the family error rate like the Bonferroni method but rather the false discovery rate, the expected fraction of null hypotheses rejected mistakenly. Because the FDR operates on achieved significance levels ( $p$ values from the Mann-Whitney test) to make inferences about a family of comparisons, it is touted as more realistic (less conservative) than the better-known Bonferroni critical value.

Computation of the dissimilarity index. To quantify dissimilarity between patterns, we sought to define a dissimilarity index (DI) that would be zero if the patterns were equal and 1 if the patterns were nonoverlapping. We defined the dissimilarity index as the number of activated glomeruli within the areas that were significantly different (as determined by the Mann-Whitney $p$ values described above) between activity patterns elicited by two different urine types divided by the total number of activated glomeruli. Thus, if the entire area was significantly different, the value of the dissimilarity index would be 1 , and if none of the areas were significantly different, the value of the dissimilarity index would be zero.

Principal component analysis. Principal component analysis uses an algorithm that reduces the dimensionality of a set of partially correlated variables by defining a small number of new variables (called principal components) that account for most of the variance in the data set. The principal components are linear combinations of the original variables and are not correlated with each other. The algorithm used in principal component analysis does not perform well with datasets including a large number of variables. The glomerular activity patterns in this manuscript each include $>1000$ bins with a non-zero number of activated glomeruli. In a principal component analysis of the raw data, the number of active glomeruli within each bin would be a separate variable. Because these datasets included $>1000$ variables, the dimensionality of the dataset had to be reduced before principal component analysis was attempted. 


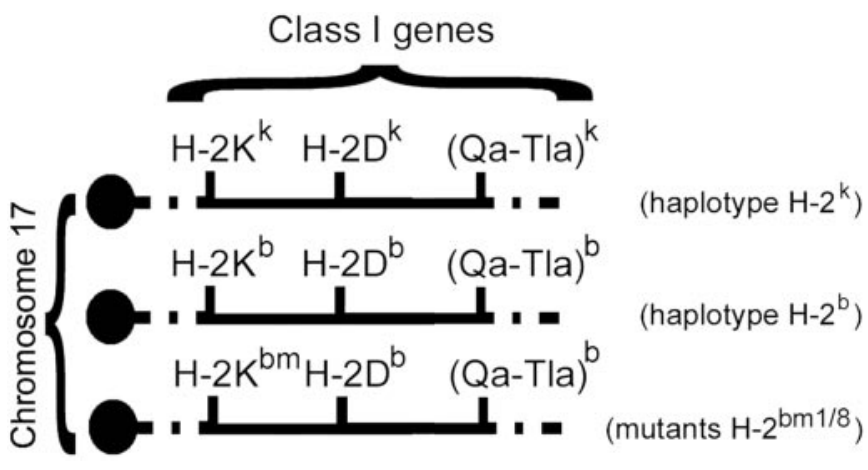

Figure 1. Diagram illustrating the urine donor genotypes. A few of the class I genes $(K, D, Q a-T 1 a)$ in the $\sim 2 \mathrm{~cm}$ region containing the $\mathrm{MHC}$ are shown. $\mathrm{H}-2^{\mathrm{n}}$ denotes haplotype. $\mathrm{H}-2 \mathrm{~N}$ indicates the gene.

We reduced the dimensionality of the dataset by (1) discarding all of those bins where the number of active glomeruli was zero in all urine types and (2) defining new variables that were sums of several variables within each dataset. To define the new variables, each bin was sorted to a different group according to which urine type elicited stimulation of the largest number of active glomeruli within each bin for those bins that were significantly different between two urine groups. Thus, for example, one group of bins was constituted of all of those bins in which urine type $\mathrm{H}-2^{\mathrm{k}}$ elicited a larger number of activated glomeruli than stimulation with any of the other urine types $\left(\mathrm{H}-2^{\mathrm{b}}, \mathrm{H}-2^{\mathrm{bm} 1}\right.$, and $\left.\mathrm{H}-2^{\mathrm{bm} 8}\right)$. A new variable was defined as the sum of the activated glomeruli within this group of bins divided by the total number of activated glomeruli. The new variable in this particular example included 52 bins, most located in the anterior ventral area where $\mathrm{H}-2^{\mathrm{k}}$ elicits robust activation (see Fig. $3 E$ ). Using this procedure, the number of variables was reduced from $>1000$ to 58 .

The reduced number of variables was subjected to a principal component analysis with a normalized varimax rotation using STATISTICA. This resulted in extraction of three principal components explaining 50\% of the variance in the dataset.

Pattern analyses of gas chromatography peaks. Two types of pattern analyses were conducted, including principal component analysis (as described above) and hierarchical cluster analysis using Ward's Method for defining Euclidian distances. Ward's Method, which uses an increase in the sum of squares, was performed using Statistics Toolbox with MATLAB (The Math Works, Inc., Natick, MA). Hierarchical cluster analysis is a statistical method for finding relatively homogeneous clusters of cases based on measured characteristics. It starts with each case in a separate cluster and then combines the clusters sequentially, reducing the number of clusters at each step until only one cluster is left. When there are $N$ cases, this involves $N-1$ clustering steps, or fusions. The hierarchical clustering process is represented as a tree where each step in the clustering process is illustrated by a join of the tree. The vertical scale corresponds to the linkage distances obtained from the hierarchical cluster analysis.

\section{RESULTS}

\section{Analysis of urine odor composition from mice differing at the MHC}

Analysis of peak heights in gas chromatographs of urine samples (as percentage of total) was undertaken for 41 representative peaks (most likely compounds) present in adult male urine. Individual samples of urine from mice representing each of four genotypes $\left(\mathrm{H}-2^{\mathrm{k}}, \mathrm{H}-2^{\mathrm{b}}, \mathrm{H}-2^{\mathrm{bm} 1}\right.$, and $\left.\mathrm{H}-2^{\mathrm{bm} 8}\right)$ (Figs. 1, 2) were used to determine the relative pattern of the 41 volatiles for each individual and their respective genetic group. Although it is unknown which, if any, of these distinct compounds are actually used in odor discrimination according to $\mathrm{H}-2$ type, we do know that it is likely to involve the relative amounts of certain volatiles rather than the absolute amount of one or two compounds (Singer et al., 1997). Therefore, we
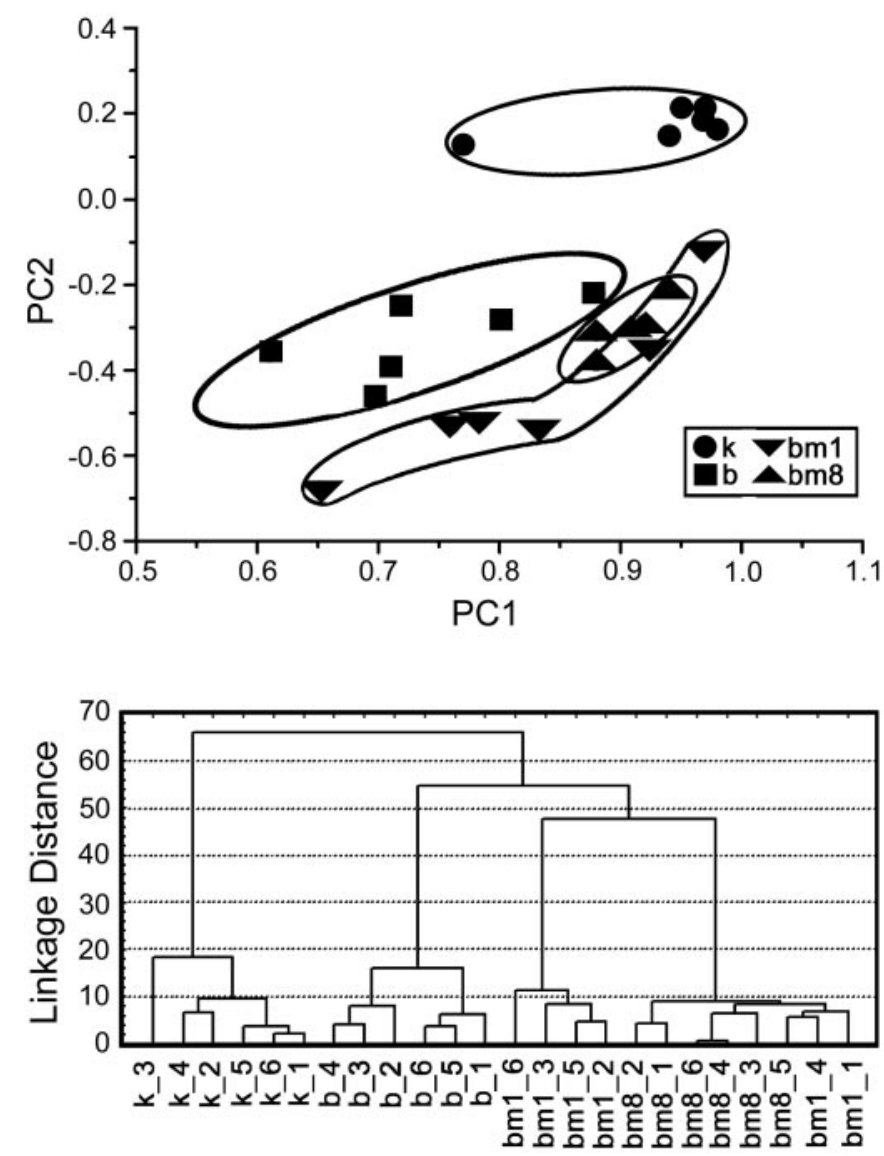

Figure 2. Pattern analyses of urine odor composition from mice differing at the MHC $\left(\mathrm{H}-2^{\mathrm{b}}, \mathrm{H}-2^{\mathrm{k}}, \mathrm{H}-2^{\mathrm{bm} 8}\right.$, and $\left.\mathrm{H}-2^{\mathrm{bm} 1}\right)$. A PCA of gas chromatograph peaks is illustrated in the top panel. The bottom panel shows a tree diagram obtained from a hierarchical clustering analysis of gas chromatograph peaks. The vertical scale corresponds to the linkage distances obtained from the hierarchical cluster analysis.

asked whether the relative proportion of volatiles of individual samples formed groups reflecting the $\mathrm{H}-2$ type of the donors. Statistical pattern analyses including Principal Component Analysis (PCA) and hierarchical analysis were conducted and are shown in Figure 2. PCA identifies "features" (components) that best discriminate patterns within a given set (Richmond and Optican, 1987), essentially by performing a highdimensional version of the linear best fit. Hierarchical cluster analysis is a statistical method for finding relatively homogeneous clusters of cases based on measured characteristics. In both the PCA and hierarchical analysis, the points corresponding to the $\mathrm{H}-2^{\mathrm{b}}$ and $\mathrm{H}-2^{\mathrm{k}}$ mice formed distinct clusters consistent with previous behavioral, chemical, and functional mapping studies (Yamazaki et al., 1990; Singer et al., 1997; Schaefer and Restrepo, 2001b). The two mutant strains (H$2^{\mathrm{bm} 8}$ and $\mathrm{H}-2^{\mathrm{bm} 1}$ ) were associated more closely with $\mathrm{H}-2^{\mathrm{b}}$ as would be expected from their genetic relationships and from behavioral studies. On the basis of these data, the mutant strains, $\mathrm{H}-2^{\mathrm{bm} 1}$ and $\mathrm{H}-2^{\mathrm{bm} 8}$, could not be discriminated; they did not fall into groups that were distinct from each other, although they were different from the two congenic strains $\mathrm{H}-2^{\mathrm{b}}$ and $\mathrm{H}-2^{\mathrm{k}}$. This too is consistent with previous behavioral studies (Yamazaki et al., 1990). 
A
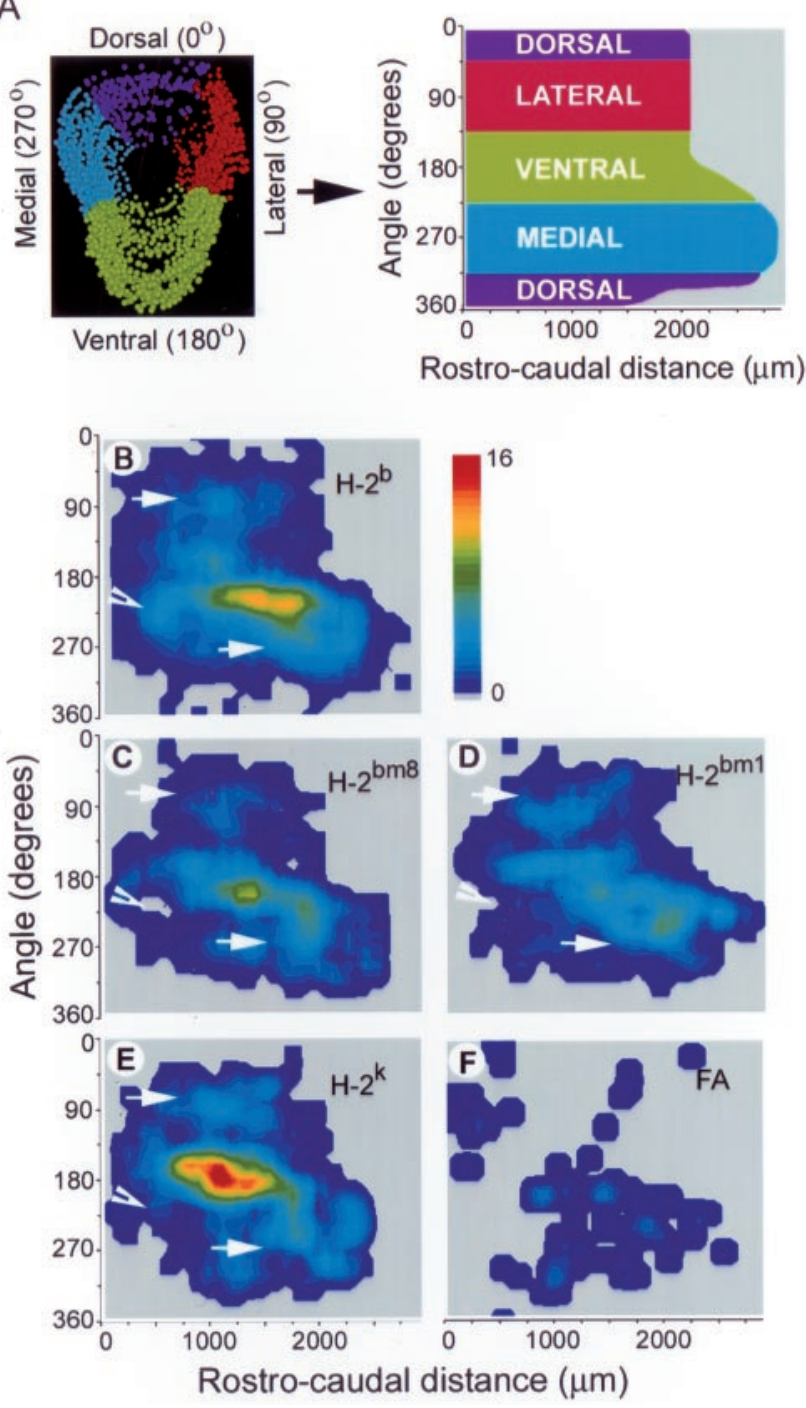

Figure 3. Average $c$-fos glomerular activation patterns for $\mathrm{H}-2^{\mathrm{b}}, \mathrm{H}-2^{\mathrm{bm} 8}$, $\mathrm{H}-2^{\mathrm{bm} 1}$, and $\mathrm{H}-2^{\mathrm{k}}$ male urine odor in the main olfactory bulbs of $\mathrm{H}-2^{\mathrm{d}}$ female mice. $A$, Schematic illustrating the positional relationship between various regions of the $\mathrm{MOB}$ and the two-dimensional contour maps. $B-F$, Color contour maps of averaged evoked glomerular activity. $B, \mathrm{H}-2^{\mathrm{b}}$ odor map $(n=8) ; C, \mathrm{H}-2^{\text {bm8 }}$ odor map $(n=7) ; D, \mathrm{H}-2^{\text {bm1 }}$ odor map $(n=8)$; $E, \mathrm{H}-2^{\mathrm{k}}$ odor map $(n=6) ; F$, control showing average map for mice exposed to fresh air $(n=3)$. Color bar to the right of $B$ shows the density of active glomeruli (number of positive glomeruli per bin) for $B-F$.

\section{Urine odors from mice differing at a single MHC gene evoke simple and stereotypic glomerular activation patterns}

Presentation of novel male urine to awake and behaving female mice results in stereotyped glomerular activation patterns as measured via mapping $c$-fos mRNA induction patterns (see Materials and Methods) (Schaefer et al., 2001b). In agreement with those previous results on congenic donor mice $\left(\mathrm{H}-2^{\mathrm{k}}\right.$ vs $\left.\mathrm{H}-2^{\mathrm{b}}\right)$, urine odor from isogenic (mutant) mice $\left(\mathrm{H}-2^{\mathrm{bm} 8}\right.$ vs $\mathrm{H}-2^{\mathrm{bm} 1}$ ) elicited activity primarily in three broad regions: ventral, lateral, and medial in average (Fig. 3) and individual maps (Fig. 4).

Earlier studies have demonstrated an axis of symmetry within each bulb that partitions the bulb into two mirror-image maps of the glomeruli (Nagao et al., 2000). In situ hybridization shows that the glomeruli representing the same olfactory receptor (OR) are symmetrically arranged: one in a domain in the lateral hemisphere and the other in a corresponding domain in the medial hemisphere of the MOB (Ressler et al., 1994; Vassar et al., 1994; Mombaerts, 1999). In addition, mirror images are apparent in functional odor maps (Guthrie and Gall, 1995a; Johnson et al., 1999; Meister and Bonhoeffer, 2001). Such a symmetry axis is visible in all of our maps. Glomerular activation is apparent in the lateral part of the bulb, with its mirror image in the medial aspect of the bulb (Fig. 3, white arrows).

The ventral region of the bulb is unique in having unpaired glomeruli (Strotmann et al., 1999). Because these glomeruli have olfactory receptor neurons that express ORs without an identical partner elsewhere in the MOB, they probably do not participate in a symmetry map. We have found that the largest region evoked by urine odor is ventral (Fig. $3 B-F$ ). Interestingly, only a small number of the monomolecular odorants that have been mapped in the bulb have been shown to activate the extreme ventral aspect (Johnson et al., 2002) (also see http://leonlab.bio.uci.edu/).

Approximately $10 \%$ of the total bulb glomeruli were activated in response to presentation of urine, whereas fewer glomeruli (1-2\%) were activated in the fresh air controls. Specifically, the number of activated glomeruli in mice exposed to $20 \% \mathrm{v} / \mathrm{v}$ of urine odor was $225 \pm 45$ for $\mathrm{H}-2^{\mathrm{b}}(n=8), 150 \pm 26$ for $\mathrm{H}-2^{\mathrm{bm} 1}$ $(n=8), 155 \pm 18$ for $\mathrm{H}-2^{\mathrm{bm} 8}(n=7)$, and $231 \pm 32$ for $\mathrm{H}-2^{\mathrm{k}}(n=$ 6) genotypes.

\section{Urine odors from mice differing at a single MHC gene evoke unique glomerular activation patterns}

Even from casual inspection, it was evident that each urine odor map is unique (Fig. 3). Our initial observations suggested that there were small shifts of glomerular activity within and around the ventral region (Fig. 3, white arrowheads). To obtain objective quantitative confirmation of the uniqueness of the overall representation for each urine type in the MOB, the $c$-fos mRNA expression patterns were subjected to PCA (Ribeiro et al., 1998). Figure 4 shows the first three principal components of the resulting PCA and projections of individual urine odor maps onto a plane of the three-dimensional space defined by the first three components. The variables used as input for the PCA were combinations of the original variables (each $10^{\circ} \times 72 \mu \mathrm{m}$ bin was sorted to a different group according to which urine type elicited stimulation of the largest number of active glomeruli within each bin for those bins that were significantly different between two urine groups). The principal components are linear combinations of these variables and not correlated with each other. Figure $4 \mathrm{~A}$ shows a simplified version of the first three components where each bin is shown as either green, magenta, or pale blue when factor loadings (a measure of the contribution of each variable to each principal component) in each principal component are $>0.5$. We found that the first two components could completely separate the congenic urines $\left(\mathrm{H}-2^{\mathrm{k}}\right.$ and $\left.\mathrm{H}-2^{\mathrm{b}}\right)$ (Fig. $\left.4 B\right)$. A third component was needed to further separate the mutants $\left(\mathrm{H}-2^{\mathrm{bm} 1}\right.$ and $\mathrm{H}-2^{\mathrm{bm} 8}$ ) (Fig. $4 C$ ). $\mathrm{H}-2^{\text {bm8 }}$ could be completely separated from $\mathrm{H}-2^{\mathrm{b}}$ and $\mathrm{H}-2^{\mathrm{k}}$; however, there is some intermingling of $\mathrm{H}-2^{\mathrm{bm} 1}$ with the $\mathrm{H}-2^{\mathrm{b}}$ and $\mathrm{H}-2^{\mathrm{bm} 8}$. This is not surprising because mice have a much more difficult time distinguishing between $\mathrm{H}-2^{\mathrm{b}}$ and $\mathrm{H}-2^{\mathrm{bm} 1}$ (Yamazaki et al., 1990) (also see Discussion) and $\mathrm{H}-2^{\mathrm{bm} 1}$ and $\mathrm{H}-2^{\mathrm{bm} 8}$ (our unpublished observation). These three components, based solely on the density and location of active glomeruli in the MOB, were already enough to classify and organize the patterns in $\mathrm{H}-2^{\mathrm{k}}, \mathrm{H}-2^{\mathrm{b}}$, and $\mathrm{H}-2^{\mathrm{bm} 8}$ : different families of patterns lie in different regions of the three-dimensional 
A

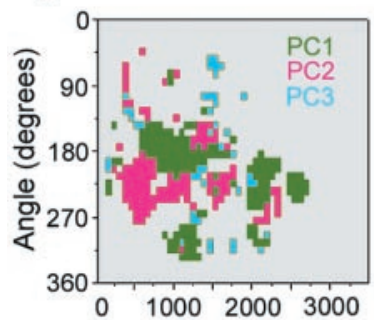

Rostro-caudal distance $(\mu \mathrm{m})$

B
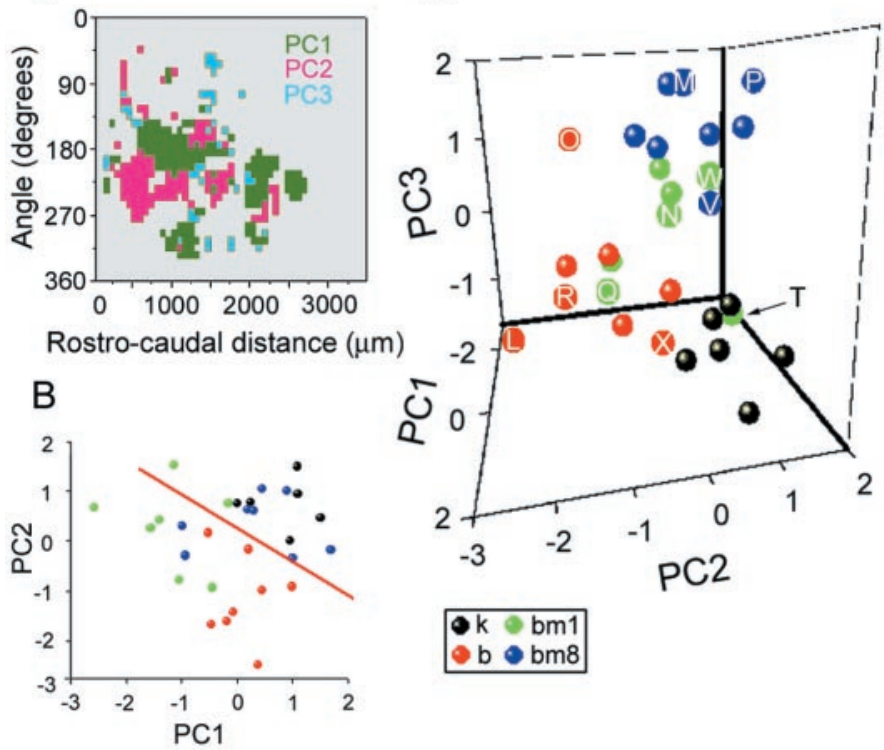

$\mathrm{k} \cdot \mathrm{bm} 1$ $b \circ \mathrm{bm} 8$
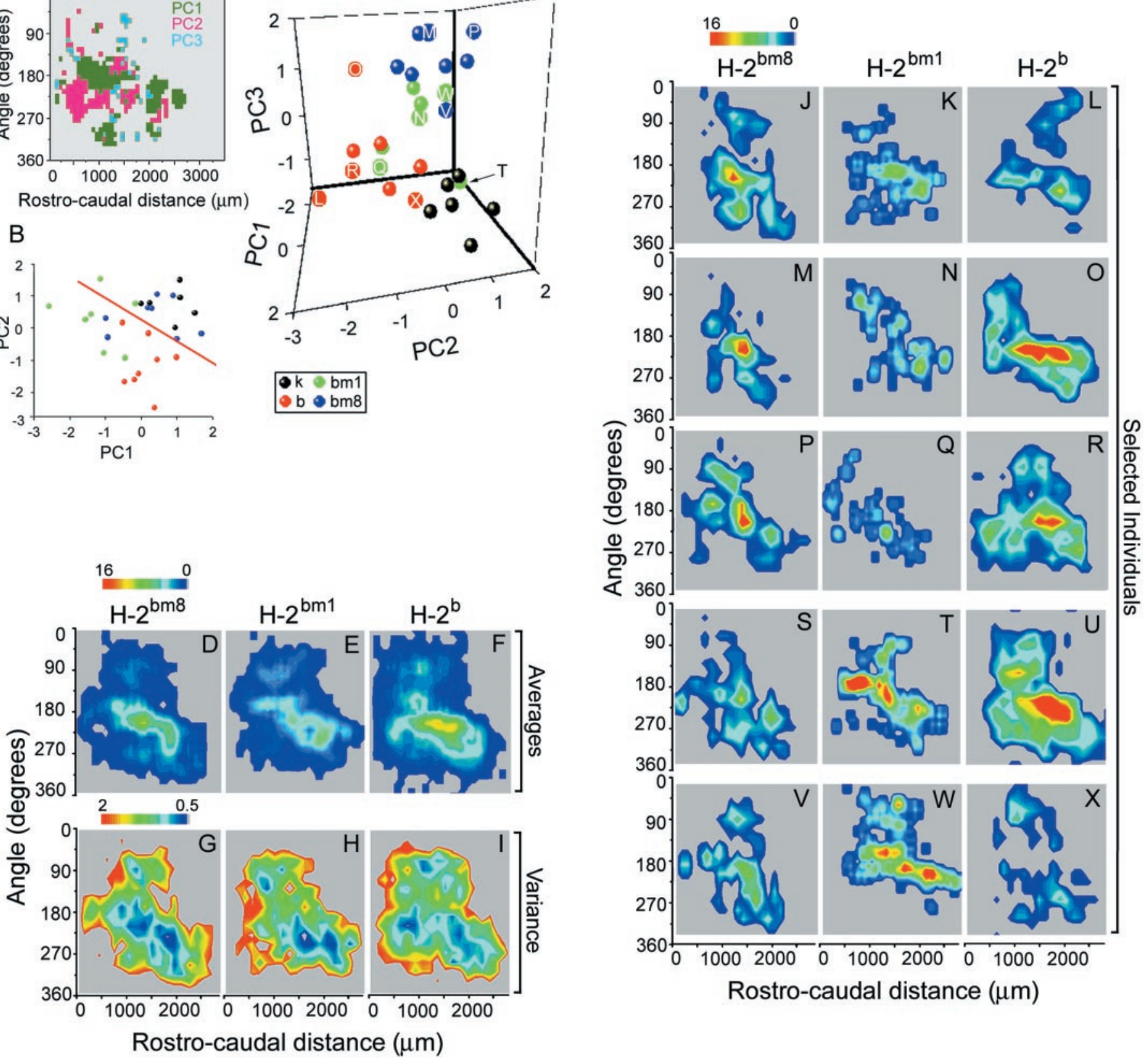

Figure 4. PCA of $c$-fos mRNA expression patterns for $\mathrm{H}-2^{\mathrm{b}}, \mathrm{H}-2^{\mathrm{k}}, \mathrm{H}-2^{\mathrm{bm} 8}$, and $\mathrm{H}-2^{\mathrm{bm} 1}$ urine odors. $A$, The location of the individual components of the resulting PCA shown in two dimensions. $B$, A plot demonstrating that the first two PCs can completely separate the congenic haplotypes $\mathrm{H}-2^{\mathrm{k}}$ and $\mathrm{H}-2^{\mathrm{b}}$. $C$, Shown is the space defined by the first three components of the PCA. Urine odors are organized into different families according to the distribution of $c$-fos mRNA glomerular activation patterns within this three-dimensional space. Each sphere represents a single mouse exposed to a single sample of urine. Spheres of the same color represent a single haplotype. $D-F, J-X, c-f o s$ glomerular activation patterns for $\mathrm{H}-2^{\mathrm{b}}, \mathrm{H}-2^{\mathrm{bm}}$, and $\mathrm{H}-2^{\mathrm{bm} 1}$ male urine odor in the main olfactory bulbs of $\mathrm{H}-2^{\mathrm{d}}$ female mice. $D-F$, Color contour maps of averaged evoked glomerular activity. $D, \mathrm{H}-2^{\text {bm8 }}$ odor map $(n=7) ; E, \mathrm{H}-2^{\mathrm{bm} 1}$ odor map $(n=8) ; F, \mathrm{H}-2^{\mathrm{b}}$ odor map $(n=8) ; G-I$, normalized SD (SD/average) maps for $\mathrm{H}-2^{\mathrm{bm} 8}(D), \mathrm{H}-2^{\mathrm{bm} 1}(E)$, and $(F) \mathrm{H}-2^{\mathrm{b}}$. $J-X$, Color contour maps of individual evoked glomerular activity. $J, M, P, S, V, \mathrm{H}-2^{\text {bm8 }}$ odor maps; $K, N, Q, T, W, \mathrm{H}-2^{\text {bm1 }}$ odor maps; $L, O, R, U, X$, $\mathrm{H}-2^{\mathrm{b}}$ odor maps. Color bar on top of $D$ and $J$ shows the density of active glomeruli (number of positive glomeruli per bin). Color bar on top of $G$ shows the range of the variability ( 2 is most variable).

space. Moreover, the PCA arranged individual members in order within their families with the exception of $\mathrm{H}-2^{\mathrm{bm} 1}$. Thus, a single gene difference results in spatial pattern differences that can be quantified for one case and not for another, but the one that worked is the key point: mice discriminated between $\mathrm{H}-2^{\mathrm{b}}$ and $\mathrm{H}-2^{\mathrm{bm} 8}$ with fewer training trials than $\mathrm{H}-2^{\mathrm{b}}$ and $\mathrm{H}-2^{\mathrm{bm} 1}$.
To obtain a better sense of how individual variation affects the overall position of the individual within its corresponding family, fractional variance and individual maps were plotted (Fig. 4D$X)$. Variability is highest along the rostrocaudal edges of the maps and probably reflects technical error in mapping (Fig. $4 G-I$ ). We have shown previously that at the $95 \%$ confidence interval, the 
region within which the molecularly defined glomerulus $\mathrm{P} 2$ lies, encompasses a domain (inter-animal) containing $\sim 2 \%$ of the glomeruli in the MOB. This estimate is similar to intra-animal variation for a glomerular domain, so we concluded that our mapping method introduces very little error beyond that found biologically (Strotmann et al., 2000). Thus, the variation in the functional maps most likely arises as a result of differences in the batches of urine (although they are from the same panel of mice), attention levels, nasal patency, and the $c$-fos in situ hybridization method. The variance is lowest for $\mathrm{H}-2^{\text {bm8 }}$ (Fig. 4C,D, G, $J, M, P, S, V)$ and $\mathrm{H}-2^{\mathrm{k}}$ (Schaefer et al., 2001b) urine odor representations as indicated by the spread of individuals in Figure $4 C$ and the level and size of the region exhibiting the lowest amount of variance Figure $4 G$. The variance is highest for $\mathrm{H}-2^{\mathrm{b}}$ (Fig. $4 C, F, I, L, O, R, U, X)$ and $\mathrm{H}-2^{\text {bm } 1}$ (Fig. $4 C, E, H, K, N, Q, T, W$ ) as indicated by the spread of individuals in Figure $4 C$ and the level and size of the regions exhibiting the lowest amount of variance (Fig. 4H,I). Interestingly, differences in the spread of individual urines as determined by their chemical composition follow this same pattern (Fig. 2). Some of the individual maps from Figure $4 J-X$ are indicated in the PCA (Fig. 4C). The most striking feature to note here is that although each urine type may give rise to some central tendency as seen in the average maps (Fig. $4 D-F)$, there is still significant and sufficient information outside these "main" areas of activation that can separate the individuals into their appropriate family (Fig. $4 L, X$ ). These results emphasize the role of the distributed pattern in coding and are consistent with a combinatorial coding scheme.

\section{The magnitude of difference between odor maps positively correlates with genetic disparity}

To determine whether there is any correlation between the extent of genetic disparity and the magnitude of difference between odor maps, we tested whether the spatial representation for urine from mice that are genetically different at a single class I gene is different from that of mice that differ at all of the class I genes.

The haplotypes used in this study are $\mathrm{H}-2^{\mathrm{k}}$ (all alleles are $\mathrm{k}$ ), $\mathrm{H}-2^{\mathrm{b}}$ (all alleles are b), and the mutants $\left(\mathrm{H}-2^{\mathrm{bm} 1}\right.$ and $\mathrm{H}-2^{\mathrm{bm} 8}$; all alleles are $\mathrm{b}$ except at the $\mathrm{K}$ gene).

A point-by-point normalized Mann-Whitney $U$ test was performed between the spatial activity maps evoked by $\mathrm{H}-2^{\mathrm{b}}$ and $\mathrm{H}-2^{\mathrm{k}}, \mathrm{H}-2^{\mathrm{b}}$ and $\mathrm{H}-2^{\mathrm{bm} 8}, \mathrm{H}-2^{\mathrm{b}}$ and $\mathrm{H}-2^{\mathrm{bm} 1}$, and $\mathrm{H}-2^{\mathrm{bm} 1}$ and $\mathrm{H}-2^{\text {bm8 }}$ (Fig. 5). Several large regions of difference were found between $\mathrm{H}-2^{\mathrm{b}}$ and $\mathrm{H}-2^{\mathrm{k}}$, in agreement with previous results (Fig. $5 A$, white arrows and arrowhead). The largest region showing a statistical difference $\left(p=0.001-10^{-6}\right)$ was found in the ventral to ventrolateral aspect that spans $>1 \mathrm{~mm}$ rostrocaudally. The regions of difference between the $\mathrm{K}^{\mathrm{b}}$ wild type $\left(\mathrm{H}-2^{\mathrm{b}}\right)$ and the $\mathrm{K}^{\mathrm{b}}$ mutants $\left(\mathrm{H}-2^{\mathrm{bm} 1}\right.$ and $\left.\mathrm{H}-2^{\mathrm{bm} 8}\right)$ were much smaller in size and overall significance (Fig. $5 B, C$, white arrows). The largest significant differences between $\mathrm{H}-2^{\mathrm{b}}$ and the mutants were in the anterior and caudal ventromedial aspects $\left(p=0.001-10^{-6}\right.$ and $10^{-5}$ for bm8 and bm1, respectively). These areas were also different between $\mathrm{H}-2^{\mathrm{b}}$ and $\mathrm{H}-2^{\mathrm{k}}$. These regions are dominated by $\mathrm{H}-2^{\mathrm{b}}$; that is, $\mathrm{H}-2^{\mathrm{b}}$ urine elicits more activity than do the others in the anterior and caudal ventromedial aspects. There was little difference between $\mathrm{H}-2^{\mathrm{bm} 1}$ and $\mathrm{H}-2^{\mathrm{bm} 8}$ (Figure $5 D$ ) and virtually none between two batches of $\mathrm{H}-2^{\mathrm{b}}$ (data not shown).

To obtain a quantitative measure of the overall magnitude of disparity between each of the pairs of maps, a pairwise DI was calculated (see Materials and Methods) (Table 1). Identical maps would have a DI of 0 . Maps that are different at every point would

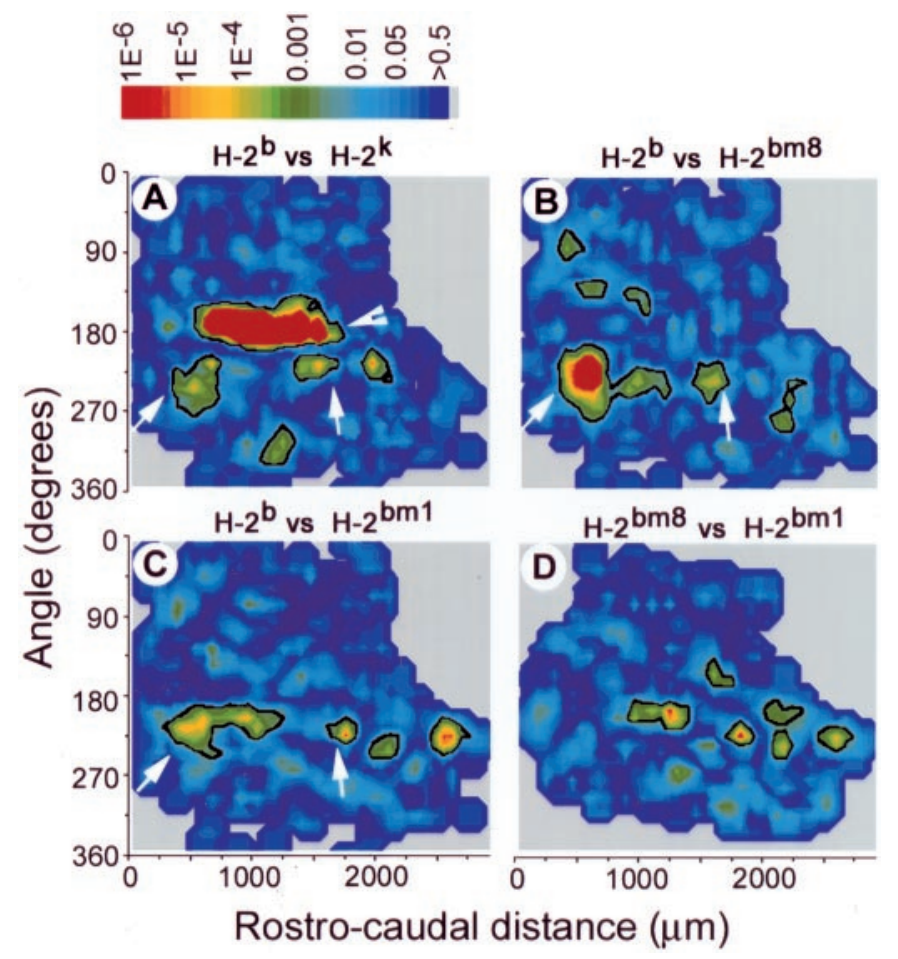

Figure 5. Mann-Whitney $U$ tests for comparison of $c$-fos glomerular activity for $\mathrm{H}-2^{\mathrm{b}}$ versus $\mathrm{H}-2^{\mathrm{k}}, \mathrm{H}-2^{\mathrm{b}}$ versus $\mathrm{H}-2^{\mathrm{bm} 8}$, and $\mathrm{H}-2^{\mathrm{b}}$ versus $\mathrm{H}-2^{\mathrm{bm} 1}$. $A-C$, Color contour maps of the difference between $\mathrm{H}-2$ odor representations. $A, \mathrm{H}-2^{\mathrm{b}}$ versus $\mathrm{H}-2^{\mathrm{k}} ; B, \mathrm{H}-2^{\mathrm{b}}$ versus $\mathrm{H}-2^{\mathrm{bm} 8} ; C, \mathrm{H}-2^{\mathrm{b}}$ versus $\mathrm{H}-2^{\mathrm{bm} 1} ; D, \mathrm{H}-2^{\mathrm{bm} 8}$ versus $\mathrm{H}-2^{\mathrm{bm} 1} \cdot p$ values for Mann-Whitney $U$ tests are shown at each bin within the map. Color bar on the top of $A$ shows the $p$ values. The black border was drawn to indicate the limits (critical value) of the FDR: $p<0.154$ in $A, p<0.053$ in $B, p<0.093$ in $C$, and $p<$ 0.081 in $D$.

have a DI of 1 . The DIs indicated that $\mathrm{H}-2^{\mathrm{b}}$ was more dissimilar to $\mathrm{H}-2^{\mathrm{k}}(0.3191)$ than it was to either $\mathrm{H}-2^{\mathrm{bm} 8}(0.2885)$ or $\mathrm{H}-2^{\mathrm{bm} 1}$ (0.1725). Comparing H-2 ${ }^{\text {bm } 8}$ versus $\mathrm{H}-2^{\mathrm{bm} 1}$ yielded the lowest DI (0.16388) among the experimental groups. To obtain a sense of how individual variability and small sample size would influence the DI, we compared old $\mathrm{H}-2^{\mathrm{b}}(n=4)$ versus new $\mathrm{H}-2^{\mathrm{b}}(n=4)$ data to obtain a DI of 0.1116 . These results show that the more genetic disparity there is between urine donors, the greater the difference in the spatial representations in the MOB.

\section{Emerging patterns in the code for MHC-determined body scents}

Urine from donor mice of four different MHC genotypes evoked glomerular activity primarily in three broad regions of the MOB: ventral, lateral, and medial. In all the representations, the ventral region exhibits the densest and largest extent of glomerular activation. Thus, the ventral region of activity dominates the overall pattern. One of the features that make each $\mathrm{H}-2$ map unique is a small shift of glomerular activity within and around the ventral region (Figs. 3, arrowheads, 5). For $\mathrm{H}-2^{\mathrm{b}}$ versus $\mathrm{H}-2^{\mathrm{k}}$ the largest region of difference is found in the ventral to ventrolateral aspect and occurs approximately mid-bulb. The two regions that differ between $\mathrm{H}-2^{\mathrm{b}}$ and the other three urine types $\left(\mathrm{H}-2^{\mathrm{k}}\right.$ or $\mathrm{H}-2^{\mathrm{bm} 1}$ or $\mathrm{H}-2^{\mathrm{bm} 8}$ ) are found in the anterior and caudal ventromedial aspects of the MOB. These spatial representations for a range of odor aromas share a basic spatial arrangement (lateral, medial, and a dominating ventral pattern) that reflects the particular aroma class (urine aroma), but they are also distinct in having 
Table 1. Behavioral discrimination data, linkage distances, and dissimilarity indices for corresponding odor comparisons

\begin{tabular}{|c|c|c|c|c|c|}
\hline & $\mathrm{H}-2^{\mathrm{b}}$ versus $\mathrm{H}-2^{\mathrm{k}}$ & $\mathrm{H}-2^{\mathrm{b}}$ versus $\mathrm{H}-2^{\mathrm{bm} 8}$ & $\mathrm{H}-2^{\mathrm{b}}$ versus $\mathrm{H}-2^{\mathrm{bm} 1}$ & $\mathrm{H}-2^{\text {bm8 }}$ versus $\mathrm{H}-2^{\mathrm{bm} 1}$ & $\mathrm{H}-2^{\mathrm{b}}$ versus $\mathrm{H}-2^{\mathrm{b}}$ \\
\hline Number of trials & 150 & 250 & 400 & $* *$ & $* *$ \\
\hline $\mathrm{LD}$ & 63.0 & 50.0 & 48.5 & & \\
\hline DI & 0.3191 & 0.2885 & 0.1725 & 0.1638 & 0.1116 \\
\hline
\end{tabular}

$* *$ indicates $\gg 500$ trials (our unpublished observations).

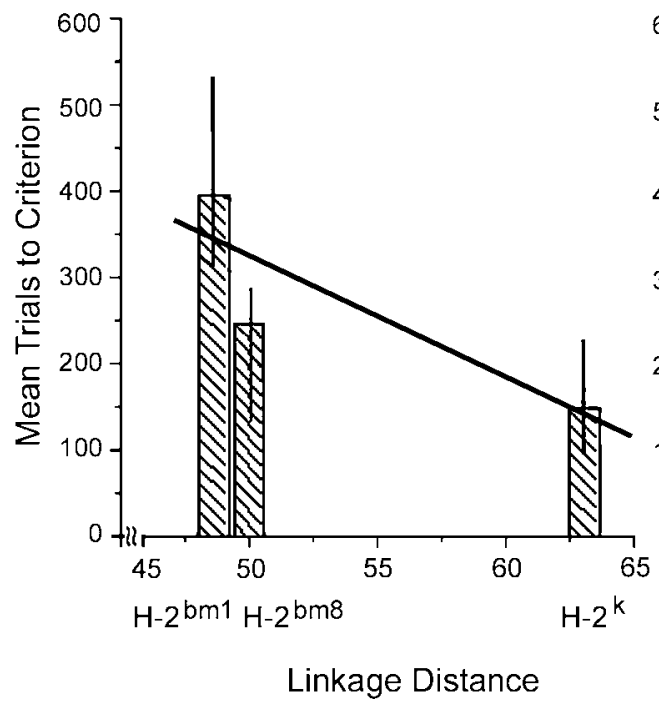

Linkage Distance

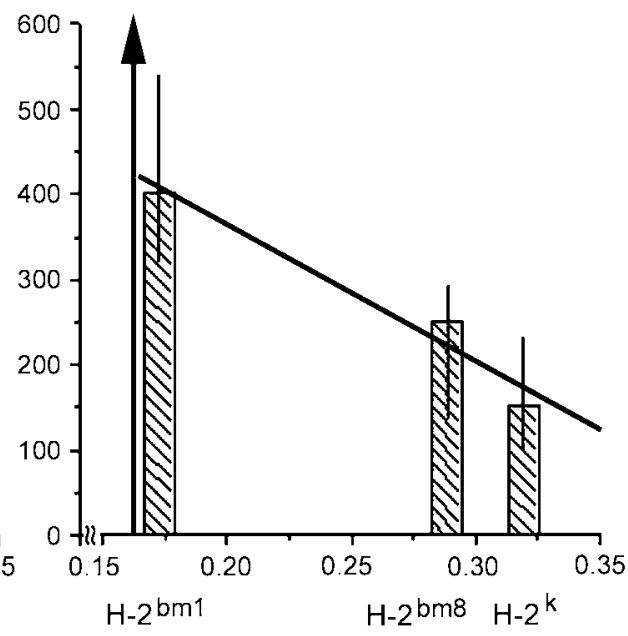

Dissimilarity Index
Figure 6. Diagram showing the correlation between the disparity in odor maps and ability to discriminate. Each comparison is shown: $\mathrm{H}-2^{\mathrm{b}}$ versus $\mathrm{H}-2^{\mathrm{k}}, \mathrm{H}-2^{\mathrm{bm} 8}$, and $\mathrm{H}-2^{\mathrm{bm} 1}$ (from our data) plotted against the mean trials to criterion (Yamazaki et al., 1990). The black arrow indicates the threshold for the ability to discriminate between two odors, and it was determined from the $\mathrm{H}-2^{\mathrm{bm} 8}$ versus $\mathrm{H}-2^{\mathrm{bm} 1}$ comparison. The black lines indicate the total range. some modification of the basic arrangement. Importantly, we would like to emphasize that it is not only the major contributing regions of activation that allow discrimination of the maps but also some of the minor contributing regions as well (Fig. 4, compare $L$ and $X$ with $F$ ). These data emphasize the importance of highly distributed patterns of activity.

\section{DISCUSSION}

In this study we tested the hypothesis that modification of a single gene (the $\mathrm{K}$ gene of the major histocompatibility locus), which results in a subtle change in the odiferous quality of urine, causes a change in the composition of urine volatiles and consequently the evoked glomerular activation pattern in the MOB. To explore the relationship between genetics, composition of urine volatiles, and the spatial representation of these complex stimuli, we used as stimuli urine from mice with a single MHC gene difference (isogenic or more specifically mutant) and compared it with urine from mice differing at all the MHC genes (congenic).

Individual odor discrimination according to $\mathrm{H}-2$ type is likely to involve the relative amounts of certain volatiles rather than the absolute amount of one or two compounds (Singer et al., 1997). Therefore, to test whether MHC gene differences result in a change in the composition of urine, we asked whether the relative proportion of volatiles of individual samples formed groups reflecting the H-2 type of the donors. By using two methods of pattern analyses, PCA and hierarchical analysis, we determined that mice differing at all $\mathrm{MHC}$ genes $\left(\mathrm{H}-2^{\mathrm{b}}\right.$ and $\left.\mathrm{H}-2^{\mathrm{k}}\right)$ formed distinct clusters consistent with previous behavioral, chemical, and functional mapping studies (Yamazaki et al., 1990; Singer et al., 1997; Schaefer and Restrepo, 2001b). In addition, mutant mice differing at only a single gene $\left(\mathrm{H}-2 \mathrm{~K}^{\mathrm{bm} 8}\right.$ and $\left.\mathrm{H}-2 \mathrm{~K}^{\mathrm{bm} 1}\right)$ were more closely associated with wild type $\left(\mathrm{H}-2 \mathrm{~K}^{\mathrm{b}}\right)$, as would be expected from their genetic relationships and from behavioral studies. The mutant strains, $\mathrm{H}-2^{\mathrm{bm} 1}$ and $\mathrm{H}-2^{\mathrm{bm} 8}$, did not fall into groups that were distinct from each other, although they were different from the two congenic strains $\mathrm{H}-2^{\mathrm{b}}$ and $\mathrm{H}-2^{\mathrm{k}}$.

To determine whether there is any relationship between the extent of linkage distance in the hierarchical cluster analysis and an animal's ability to discriminate those odors, the linkage distances were plotted against previously published behavioral discrimination data (Fig. 6, Table 1) (Yamazaki et al., 1990). The behavioral discrimination data were obtained using $y$-maze experiments (see also Carroll et al., 2002). It is assumed that the more difficult it is to discriminate two odorants, the more training trials are required to reach the performance criterion $(80 \%$ correct responding). Thus, the similarity of these chemical patterns as determined by linkage distance reflects the qualitative similarity of the odors as deduced from previous studies of odor discriminatory ease.

In contrast with Yamazaki et al. (1983), Carroll et al. (2002) failed to find a discrimination between urines from $\mathrm{F}_{2}$ C57BL/6$\mathrm{H}-2^{\mathrm{b}}$ (b) versus C57BL/6-H-2 ${ }^{\text {bm1 }}$ (bm1) animals. In the Yamazaki et al. (1983) study, all $\mathrm{F}_{2}$ data were obtained from mice whose only training was on $b$ versus bm1-inbred urines. From these data, it can be concluded that (1) the odors of this pair differ as a function of genetic differences in the $\mathrm{K}$ gene itself and (2) there is a commonality in the odor differences between the inbred pair and the $\mathrm{F}_{2}$ pair. A parallel study with the $\mathrm{F}_{2}$ b versus $\mathrm{C} 57 \mathrm{BL} / 6-\mathrm{H}-2^{\mathrm{b}}(\mathrm{b})$ urines was never conducted, so we are not absolutely certain that these differences are attributable entirely to changes in the $\mathrm{K}$ gene as distinct from hypothetical changes in other parts of the genome. Nevertheless, animals trained to discriminate b versus bm1 (both inbred) generalized this response to b versus bm8 (both inbred); this indicates that the major odor difference between these pairs is caused by variation in the $\mathrm{K}$ gene itself. 
In contrast with our earlier studies in which differences were large between the spatial activity maps evoked by urine from $\mathrm{H}-2^{\mathrm{k}}$ and $\mathrm{H}-2^{\mathrm{b}}$ haplotypes (all class I genes are different), differences in a single gene, $\mathrm{H}-2 \mathrm{~K}$, elicit much smaller differences. Specifically, $\mathrm{H}-2^{\mathrm{b}}$ versus $\mathrm{H}-2^{\mathrm{k}}$ urine odor maps differ in a large region spanning rostrocaudally in the ventral to ventrolateral aspect of the MOB that is dominated by $\mathrm{H}-2^{\mathrm{k}}$. Also, there are smaller regions in the anterior and posterior ventromedial aspects that are dominated by $\mathrm{H}-2^{\mathrm{b}}$. As is the case for $\mathrm{H}-2^{\mathrm{k}}, \mathrm{H}-2^{\mathrm{bm} 8}$ and $\mathrm{H}-2^{\mathrm{bm} 1}$ also have two small regions in the anterior and posterior ventromedial aspect that differ from $\mathrm{H}-2^{\mathrm{b}}$ as a result of the dominance of $\mathrm{H}-2^{\mathrm{b}}$ in that region. Thus, one could consider $\mathrm{H}-2^{\mathrm{b}}$ as having some component(s) that is not present in $\mathrm{H}-2^{\mathrm{k}}, \mathrm{H}-2^{\mathrm{bm} 8}$, and $\mathrm{H}-2^{\mathrm{bm} 1}$ that gives rise to the differences seen in the ventromedial aspects. Next, we asked whether the extent of spatial differences in the odor maps was related to how genetically different the donor mice were. By comparing urine odors from mice that differed by a single gene with urine obtained from mice that differed at many genes throughout the MHC, we found that the extent of spatial difference or magnitude of disparity in the odor maps was positively related to genetic disparity (and presumably odor composition). Each map was unique as a result of shifts in activity within and around the ventral region. The more genetically different the mice were, the larger the shifts of activity.

The principal component analysis in Figure $4 C$ showed that the spatial activity patterns, elicited specifically by those odors that are discriminated behaviorally (bm8 vs b and k vs b), fall within nonoverlapping volumes (e.g., different groups or families) in a three-dimensional space defined by the first three principal components. Importantly, each sphere, representing an individual mouse, falls within nonoverlapping volumes for bm8 versus $b$ and b versus $k$ (Fig. $4 C$ ).

If information content pertinent to odor identity is encoded in neural space, then it would logically follow that the more spatially different two odor representations are in the MOB, the easier the stimuli would be to behaviorally discriminate. To determine whether there is any relationship between the magnitude of disparity in odor maps and an animal's ability to discriminate those odors, the DIs mentioned earlier for $\mathrm{H}-2^{\mathrm{b}}$ versus $\mathrm{H}-2^{\mathrm{k}}$, $\mathrm{H}-2^{\mathrm{b}}$ versus $\mathrm{H}-2^{\mathrm{bm} 8}$, and $\mathrm{H}-2^{\mathrm{b}}$ versus $\mathrm{H}-2^{\mathrm{bm} 1}$ were plotted against previously published behavioral discrimination data (Fig. 6, Table 1) (Yamazaki et al., 1990).

Here we show a relationship between the extent of difference in the spatial activity maps and the ability to distinguish the odors [see Linster et al. (2001) for a similar result for nonspeciesspecific odors]. The more different two spatial activity maps are, the easier it is for mice to discriminate. The linearity between the extent of spatial disparity in odor maps and the ability to discriminate the odors breaks down between the comparisons $\mathrm{H}-2^{\mathrm{b}}$ versus $\mathrm{H}-2^{\mathrm{bm} 1}$ and $\mathrm{H}-2^{\mathrm{bm} 8}$ versus $\mathrm{H}-2^{\mathrm{bm} 1}$ where the line becomes asymptotic because of the inability of mice to discriminate the odors (Fig. 6, black arrow). This relationship is of particular importance to coding and supports the notion that the spatial representation of a complex odorant is tightly linked to perception. Most likely, spatial and temporal information are both important for odor quality coding. Temporal information may help to strengthen the odor representation by amplifying signals from mitral cells projecting to the most strongly activated glomeruli (Mori et al., 1999; Shoppa and Westbrook, 2001).

As a result of studying a naturally occurring complex object, we not only provide information pertaining to how natural multicomponent odors are represented in the brain, but also provide relevant data on the extraordinary neuroimmunobiological problem of how mice distinguish individuals based on their MHCdetermined body scent. Regarding a mechanism for how the MHC influences body scent, our data are consistent with the peptide hypothesis (Falk et al., 1991) (for review, see Singh et al. 1987; Penn and Potts, 1998; Singh, 2001). The peptide hypothesis states that $\mathrm{MHC}$ molecules bind to allele-specific subsets of peptides having volatile metabolites that provide the odorants (Singer et al., 1997). This hypothesis holds that MHC molecules function as odorant carriers and that peptides provide the precursors of the odorants. The hypothesis is attractive because it implicates the antigen-binding site of MHC molecules in determining an individual's allele-specific odor.

Odor differences among MHC congenic strains are caused by changes in the relative amounts of the components of urinary acids, which are potentially the metabolites of MHC-bound peptides (Singer et al., 1997). Mouse urine contains abundant acidic metabolites, many of which are derived from amino acids. Moreover, an analysis of the peptide-binding specificity for class I molecules demonstrated that the amino acid substitutions in the $\mathrm{K}^{\mathrm{bm} 1}$ molecule dramatically altered its peptide preference, when compared with the wild-type $\mathrm{K}^{\mathrm{b}}$ molecule (Schumacher et al., 1992). A direct comparison of the peptide profile selected from by these molecules reveals that $\mathrm{K}^{\mathrm{bm} 1}$ binds a much smaller set of peptides that give rise to a set that is drastically different in qualitative terms from the profile observed for $\mathrm{K}^{\mathrm{b}}$. Our odor maps for $\mathrm{K}^{\mathrm{bm} 1}$ show a lower density of active glomeruli in the ventral medial aspect and thus are consistent with a partial loss of function for $\mathrm{K}^{\mathrm{bm} 1}$.

Our data demonstrate that the overall representation of "urine aroma" is found predominately in the ventral, lateral, and medial aspects of the bulb, with the ventral aspect being most prominent. This functional evidence suggests that the general quality of urine aroma may be spatially represented. Moreover, we show that genetic differences at the MHC locus, which provide a range of urine aromas, result in certain modifications, specifically, an altered density of glomerular activity within and around some portion of the odor map, but still maintain the overall spatial arrangement. Therefore, we provide functional evidence that MHC-determined urine odor identity can be encoded spatially. Furthermore, it is crucial to mention that glomeruli outside those regions of obvious activation in the average maps seem also to play a role in encoding odor identity, emphasizing the importance of the entire glomerular contribution.

In conclusion, to begin to develop some rules of coding for naturally occurring odor mixtures, we tested whether there was significant information in their spatial representations to allow for their discrimination. We report for a given class of evolutionarily important mixtures where discrimination of small differences is key to reproductive success that the spatial pattern of activity elicited in the glomerular sheet is sufficient (contains enough information) to make a distinction between these odorants. The magnitude of disparity between odor representations (1) is predictive of the extent of the urine donor's genetic disparity and odor composition and (2) positively correlates with the animal's ability to behaviorally discriminate.

\section{REFERENCES}

Boyse EA, Beauchamp GK, Yamazaki K (1987) The genetics of body scent. Trends Genet 3:97-102.

Bishop JO, Clark AJ, Clissold PM, Hainey S, Francke U (1982) Two main groups of mouse major urinary protein genes, both largely located on chromosome 4. EMBO J 1:615-620. 
Carroll LS, Penn DJ, Potts WK (2002) Discrimination of MHC-derived odors by untrained mice is consistent with divergence in peptidebinding region residues. Proc Natl Acad Sci USA 99:2187-2192.

Curran-Everett D (2000) Multiple comparisons: philosophies and illustrations. Am J Physiol 279:R1-R8.

Falk K, Rotzschke O, Stevanovic S, Jung G, Rammensee HG (1991) Allele-specific motifs revealed by sequencing of self-peptides eluted from MHC molecules. Nature 351:290-296.

Guthrie KM, Gall CM (1995a) Functional mapping of odor-activated neurons in the olfactory bulb. Chem Senses 20:271-282.

Guthrie KM, Gall CM (1995b) Odors increase Fos in olfactory bulb neurons including dopaminergic cells. NeuroReport 6:2145-2149.

Guthrie KM, Anderson AJ, Leon M, Gall C (1993) Odor-induced increases in $c$-fos mRNA expression reveal an anatomical "unit" for odor processing in olfactory bulb. Proc Natl Acad Sci USA 90:3329-3333.

Hurst JL, Payne CE, Nevison CM, Marie AD, Humphries RE, Robertson DHL, Cavaggioni A, Beynon RJ (2001) Individual recognition in mice mediated by major urinary proteins. Nature 414:631-634.

Johnson BA, Leon M (1996) Spatial distribution of $\left[{ }^{14} \mathrm{C}\right] 2$-deoxyglucose uptake in the glomerular layer of the rat olfactory bulb following early odor preference learning. J Comp Neurol 376:557-566.

Johnson BA, Woo CC, Leon M (1998) Spatial coding of odorant features in the glomerular layer of the rat olfactory bulb. J Comp Neurol 393:457-471.

Johnson BA, Woo CC, Hingco EE, Pham KL, Leon M (1999) Multidimensional chemotopic responses to n-aliphatic acid odorants in the rat olfactory bulb. J Comp Neurol 409:529-548

Johnson BA, Ho SL, Xu Z, Yihan JS, Yip S, Hingco EE, Leon M (2002) Functional mapping of the rat olfactory bulb using diverse odorants reveals modular responses to functional groups and hydrocarbon structural features. J Comp Neurol 449:180-194.

Linster C, Johnson BA, Yue E, Morse A, Xu Z, Hingco EE, Choi Y, Choi M, Messiha A, Leon M (2001) Perceptual correlates of neural representations evoked by odorant enantiomers. J Neurosci 21:9837-9843.

Meister M, Bonhoeffer T (2001) Tuning and topography in an odor map on the rat olfactory bulb. J Neurosci 21:1351-1360.

Mombaerts P (1999) Molecular biology of odorant receptors in vertebrates. Ann Rev Neurosci 22:487-509.

Mori K, Nagao H, Yoshihara Y (1999) The olfactory bulb: coding and processing of odor molecule information. Science 286:711-715.

Nagao H, Yoshihara Y, Mitsui S, Fujisawa H, Mori K (2000) Two mirror-image sensory maps with domain organization in the mouse main olfactory bulb. NeuroReport 11:3023-3027.

Penn D, Potts W (1998) How do major histocompatibility complex genes influence odor and mating preferences? Adv Immunol 69:411-436.

Pomeroy SL, LaMantia AS, Purves D (1990) Postnatal construction of neural circuitry in the mouse olfactory bulb. J Neurosci 10:1952-1966.

Press WH, Teukolsky SA, Vettering WT, Flannery BP (1992) Numerical recipes in C. Cambridge, UK: Cambridge UP.

Ressler KJ, Sullivan SL, Buck LB (1994) Information coding in the olfactory system: evidence for a stereotyped and highly organized epitope map in the olfactory bulb. Cell 79:1245-1255.
Ribeiro S, Cecchi GA, Magnasco MO, Mello CV (1998) Toward a song code: evidence for a syllabic representation in the canary brain. Neuron 21:359-371.

Richmond BJ, Optican LM (1987) Temporal encoding of twodimensional patterns by single units in primate inferior temporal cortex. II. Quantification of response waveform. J Neurophysiol $57: 147-161$

Schaefer ML, Finger TE, Restrepo D (2001a) Variability of position of the P2 glomerulus within a map of the mouse olfactory bulb. J Comp Neurol 436:351-362.

Schaefer ML, Young DA, Restrepo D (2001b) Olfactory fingerprints for major histocompatibility complex-determined body odors. J Neurosci 21:2481-2487.

Schumacher TN, Van Bleek GM, Heemels MT, Deres K, Li KW, Imarai M, Vernie LN, Nathenson SG, Ploegh HL (1992) Synthetic peptide libraries in the determination of $\mathrm{T}$ cell epitopes and peptide binding specificity of class I molecules. Eur J Immunol 22:1405-1412.

Shoppa NE, Westbrook GL (2001) Glomerulus-specific synchronization of mitral cells in the olfactory bulb. Neuron 31:639-651.

Siegel S (1956) . Nonparametric statistics for the behavioral sciences. New York: McGraw-Hill.

Singer AG, Beauchamp GK, Yamazaki K (1997) Volatile signals of the major histocompatibility complex in male mouse urine. Proc Natl Acad Sci USA 94:2210-2214.

Singh PB (2001) Chemosensation and genetic individuality. Reproduction 121:529-539.

Singh PB, Brown RE, Roser B (1987) MHC antigens in urine as olfactory recognition cues. Nature 327:161-164.

Strotmann J, Hoppe R, Conzelmann S, Feinstein P, Mombaerts P, Breer H (1999) Small subfamily of olfactory receptor genes: structural features, expression pattern and genomic organization. Gene 236:281-291.

Strotmann J, Conzelmann S, Beck A, Feinstein P, Breer H, Mombaerts P (2000) Local permutations in the glomerular array of the mouse olfactory bulb. J Neurosci 20:6927-6938.

Vassar R, Chao SK, Sitcheran R, Nuñez JM, Vosshall LB, Axel R (1994) Topographic organization of sensory projections to the olfactory bulb. Cell 79:981-991.

Wysocki CJ, Yamazaki K, Curran M, Wysocki LM, Beauchamp GK (2001) Removal of the vomeronasal organ does not disrupt recognition of MHC-determined individual odor type. Chem Senses 101:1058.

$\mathrm{Xu}$ FQ, Greer CA, Shepherd GM (2000) Odor maps in the olfactory bulb. J Comp Neurol 422:489-495.

Yamazaki K, Beauchamp GK, Egorov IK, Bard J, Thomas L, Boyse EA (1983) Sensory distinction between $\mathrm{H}-2^{\mathrm{b}}$ and $\mathrm{H}-2^{\mathrm{bm} 1}$ mutant mice. Proc Natl Acad Sci USA 80:5685-5688.

Yamazaki K, Beauchamp GK, Bard J, Boyse EA (1990) Chemosensory identity and the Y chromosome. Behav Genet 20:157-165.

Yamazaki K, Beauchamp GK, Singer A, Bard J, Boyse EA (1999) Odor types: their origin and composition. Proc Natl Acad Sci USA 96:15221525. 